\title{
PENSAR AS JUVENTUDES CONTEMPORÂNEAS É PENSAR O CURRÍCULO E 0 ENSINO DE GEOGRAFIA
}

\author{
Thinking of contemporary youth is thinking of the curriculum and the teaching of geography
}

\author{
Victor Hugo Nedel Oliveira* \\ Miriam Pires Corrêa de Lacerda**
}

*Professor de Geografia do Colégio de Aplicação da UFRGS - victornedelcap@gmail.com. **Professora da Universidade Feevale - miriamlacerda@feevale.com.br

Recebido em 14/08/2018. Aceito para publicação em 25/08/2018.

Versão online publicada em 20/11/2018 (http://seer.ufrgs.br/paraonde)

\begin{abstract}
Resumo: 0 jovem contemporâneo vem questionando a sociedade nos mais diferentes setores. Este mesmo jovem encontra-se em nossos bancos escolares e, por vezes, não damos a devida atenção às suas individualidades, coletividades e expressões. Esta pesquisa trata das culturas juvenis no âmbito escolar e suas relações com o ensino da Geografia. Objetivou-se levantar referencial teórico para colocar em diálogo as duas grandes linhas de investigação da pesquisa: as culturas juvenis e o ensino de Geografia. Para atingir o principal objetivo proposto, foi realizada ampla pesquisa teórica sobre os dois temas da investigação. Os resultados da pesquisa indicam que o jovem contemporâneo é composto de múltiplas e transitórias identidades e está adaptando-se a múltiplos pertencimentos. Entende-se que o perfil de jovem elencado pela pesquisa pode ser assim entendido em outros espaços, na medida em que vai se moldando a estas configurações identitárias. No tocante à Geografia escolar, nos ficou bem claro que o jovem-aluno vincula muito fortemente aos temas físicos da ciência. Há o questionamento, então, sobre a condução das aulas de Geografia, no ensino básico, a saber, se as mesmas dão conta do conceito pleno do espaço geográfico, no sentido de trabalhar as temáticas físicas, mas também as humanas da ciência. Percebemos que há relação direta entre as práticas juvenis e possíveis temas a serem trabalhados na aula de Geografia. Há muito que se avançar neste tipo de pesquisa, uma vez que tratamos, além dos objetos já previstos, da prática docente.
\end{abstract}

Palavras-chave: jovens; juventudes; ensino; geografia.

\begin{abstract}
The younger contemporary society has been surprising in many different sectors. This same young man is in our school benches and sometimes we do not give due attention to their individualities, communities and expressions. This research deals with the youth cultures in the school environment and their relationship to the teaching of geography. We aim to raise theoretical framework to put in dialogue the two main lines of research inquiry: youth cultures and teaching of Geography. To achieve the main objective proposed, extensive theoretical research on the two subjects of the investigation was carried out and in the end, related the same. The survey results indicate that the contemporary young student is composed of multiple and transient identities and thereby is adapted to multiple affiliations. Even in the case of a specific reality that was analyzed, we understand that the young profile part listed by the survey can be well understood in other areas, insofar as these will be shaping the identity configurations. With regard to school Geography, in became clear that the young student linked very strongly to physical science topics. There is the question, then, on the conduct of Geography lessons in primary education, namely, whether they realize the full concept of geographical space in order to work the physical issues but also human science. We realize that there is relationship between youth practices and possible topics to be worked in geography class. There is much to advance this type of research, besides the objects already provided in teaching practice.
\end{abstract}

Key-words: Youth; Education; Geography.

\section{PARA INÍCIO DE CONVERSA...}

Somos tão jovens? Ainda persiste, em nossa sociedade, a busca pela eterna beleza, a eterna juventude? E o sonho de beber o elixir mágico da juventude e não envelhecer mais? Por longos anos a juventude foi tema de debate dos gregos e seus sucessores. Atualmente, vemos os avanços das áreas médicas em postergar a velhice. As capas de revista, apresentando formas jovens e esculturais, formando um ideal de beleza quase 
utópico. Mas não é sobre esta juventude que este trabalho se dispõe a tratar. Aqui, queremos discutir sobre essa fase que todos passamos: a juventude - que, por vezes se estende muito além do delimitado pela idade e suas relações com a Geografia, enquanto disciplina escolar e, por consequência, formadora de cidadãos presentes e atuantes no mundo. Queremos ver mais de perto as diferentes culturas juvenis e como podem nos ajudar a docenciar em geografia.

Esta pesquisa tratou-se de revisão bibliográfica sobre os dois temas centrais a que a mesma propõe-se a discutir: o conceito de juventude contemporânea/culturas juvenis e suas relações com o ensino de Geografia. Neste sentido, para justificar a necessidade de elaboração da pesquisa teórico-bibliográfica, elencou-se, na literatura existente, textos que trabalhassem os dois temas ao mesmo tempo.

A pesquisa-inventário sobre textos de pesquisas (artigos, dissertações e teses) que possivelmente envolvem as duas áreas da presente pesquisas se deu através de repositórios digitais nacionalmente conhecidos, como o Sistema de Bibliotecas da UFRGS, o Sistema de Bibliotecas da USP e o Sistema de Bibliotecas da UFG. A escolha por essas três universidades, para pesquisar especificamente sobre o tema, se dá pela consolidação de linhas de pesquisa na área do ensino de Geografia há mais tempo no país. Em relação aos artigos acadêmicos sobre o assunto, foram pesquisados no banco de dados da CAPES, no repositório Scielo e no Google acadêmico. Para que houvesse uma padronização nas pesquisas, foram colocadas quatro palavras-chave em todos os sistemas, a saber: juventude; culturas juvenis; Geografia; e ensino.

Dessa forma, ao longo da pesquisa - e pesquisar é, efetivamente, um trabalho árduo - encontrou-se alguns textos que, de maneira um pouco tímida ou por vezes tangenciada, tocam nas relações desses referenciais: jovens e ensino de Geografia.

Ao final da escrita do presente texto, deparamo-nos com a Dissertação de Mestrado de Ferreira (2014), intitulada "Canoas como lugar: o mundo dos jovens contemporâneos a partir de suas representações sociais". Ferreira (2014) apresenta as relações de jovens concluintes do ensino fundamental, de duas escolas municipais da cidade de Canoas (RS), com o conceito geográfico do lugar, através da construção de fanzines em sala de aula. A autora apresenta referencial teórico denso no que diz respeito ao ensino de Geografia. Por outro lado, não utiliza os mesmos referenciais teóricos do presente trabalho ao tratar da categoria "jovem" com maior intensidade do que tratamos aqui, enquanto "cultura juvenil", uma vez que são conceitos distintos.

Um texto importante, também encontrado durante as pesquisas com o intuito de montar um breve estado da arte do tema aqui desenvolvido, foi o artigo de Pires, Simão e Pozzer (2013), intitulado: "Representações Espaciais, Juventude e Periferia: Guajuviras/Canoas/RS e seus desafios urbanos". Coincidências à parte, o artigo publicado também se refere aos jovens do município de Canoas (RS), relacionando, aqui, com os conceitos de Lugar e Território, e, a partir dessas análises, cita as tramas de relações das representações sociais que esses jovens (de 15 a 25 anos, alunos de uma escola pública estadual) realizam em torno de seus espaços.

O terceiro texto encontrado é o artigo de Cavalcanti (2011), denominado "Aprender sobre a cidade: a geografia urbana brasileira e a formação dos jovens escolares", que trata de uma pesquisa que investiga a contribuição da Geografia urbana na formação dos jovens escolares. O texto afirma que a juventude é uma categoria social e avalia as potencialidades do ensino da Geografia urbana na formação cidadã dos jovens alunos.

Por fim, o quarto texto encontrado, dentro dos moldes de pesquisa elencados anteriormente, traz uma relação nem tímida nem tangencial ao tema proposto para a presente pesquisa, visto que foi elaborado por duas autoras das duas áreas propostas nesta investigação: ensino de Geografia e culturas juvenis. O texto intitulado "Geografando práticas juvenis que (de)marcam a metrópole: uma questão de currículo escolar?", de autoria de Garbin e Tonini (2012), traz à tona a questão dos pertencimentos identitários dos sujeitos jovens ao (de)marcarem a metrópole, através de pichações ou grafites. O texto traz à discussão o referencial teórico adotado pela pesquisa: as culturas juvenis, e o relaciona com a temática urbana. É notória a presença desses elementos urbanos em nossas cenas cotidianas na cidade: grafites e pichações, e sabemos que os mesmos, em sua grande maioria, são produzidos por jovens que, por sua vez, estão em nossos bancos escolares. Se os mesmos percebem ou não a relação dessas atitudes com os conceitos geográficos de lugar e território, por exemplo, é o que procuraremos investigar ao longo do texto. Afirmam Garbin e Tonini (2012, p. 16) que "[...] é preciso que saibamos que os processos cotidianos de fragmentação somados ao poder da cultura da massa, inscrita em códigos e estilos, gestos e performances, têm nas cenas juvenis um terreno próprio para a formação de identidades". 
Pois, nesse entendimento, há que se manter sempre presentes as importantes relações conceituais da Geografia no âmbito da sala de aula. O trabalho constante com os conceitos geográficos aqui cercados, como lugar e território, estão presentes nas culturas juvenis, mesmo por vezes não sendo explicitados/correlacionados nas aulas de Geografia.

\section{DE JOVENS CONTEMPORÂNEOS}

Ao entrar em uma sala de aula, é impossível não notar a presença deles. Estão à nossa frente, falam com linguagem própria, gesticulam, utilizam vestimenta própria, escutam música, digitam no celular: são os jovens contemporâneos. Meu interesse em entendê-los mais e melhor partiu de reflexões que iniciei em meu cotidiano docente, questionando-me sobre comportamentos juvenis que percebi e percebo em meus alunos. Durante a etapa formativa em aulas no mestrado, cursei a disciplina "Introdução aos estudos sobre juventudes na perspectiva dos estudos culturais", no Programa de Pós-Graduação da Faculdade de Educação da UFRGS. Nessa disciplina tive a oportunidade de aprofundar e discutir muito do que vejo em sala de aula e, de certa forma, contribuir na discussão que ora é apresentada, bem como na sistematização metodológica que a posteriori será encaminhada no presente. A principal categoria de análise da pesquisa é, portanto, a de "Juventudes". Essa temática das culturas juvenis é amplamente trabalhada por Feixa (1998, p. 32), quando afirma que:

En un sentido amplio, las culturas juveniles se refieren a la manera en que las experiencias sociales de los jóvenes son expresadas colectivamente mediante la construcción de estilos de vida distintivos, localizados fundamentalmente en el tiempo libre, o en espacios intersticiales de la vida institucional.

Observamos, nos estudos de Feixa (1998), que as culturas juvenis se formam na coletividade. É claro que existem muitos espaços não formais de aprendizagem e que os jovens se encontram em muitos outros espaços. Além de investigar os espaços não formais de aprendizagem, este estudo propõe-se a verificar os comportamentos e falas dos sujeitos-jovens-alunos e sua relação com o ensino da Geografia.

Feixa (2004, p. 78) complementa sua definição de juventudes como sendo

[...] uma fase natural do desenvolvimento humano que se encontraria em todas as sociedades e momentos históricos, explicado pela necessidade de um período de preparação e amadurecimento entre a dependência infantil e a plena inserção social.

E essa fase de entremeio entre a infância e a inserção social, se definida em termos de escolarização, encontra seu encaixe no ensino médio, época escolar que varia, regularmente, dos 15 aos 17 anos de idade. Caberia questionar aqui o papel da formação do ensino médio nessa etapa de preparação e amadurecimento. Como nossos currículos vêm tratando essas questões? É possível que a formação do aluno abarque, para além dos programas curriculares, uma formação plena e cidadã? Como ensinamos Geografia aos nossos alunos? Percebemos, na história brasileira, que as juventudes normalmente foram grupo integrante, atuante, pensante e participante de muitos movimentos sociais e políticos. Entretanto, nosso aluno hoje possui senso crítico de sua realidade e executa, de fato, algo para mudá-la? Nesse caso, também entra em cena o papel da formação da Geografia, no sentido de discutir os temas atuais da sociedade brasileira com os alunos. CacciaBava e Costa (2004, p. 15) já afirmaram esse histórico da juventude brasileira, ao proferir que

[...] a formulação de uma primeira síntese da história da juventude brasileira permitiu-nos identificar um traço constante que caracteriza os grupos e movimentos de jovens: a ingenuidade e a honestidade. A exposição das motivações e intenções culturais e políticas apareceu como traço marcante da condição juvenil, que rejeitaria o maquiavelismo como forma de ser dominante. [grifo nosso].

Nesse sentido, cabe lembrar que rebeldia, inquietação e inconformidade fazem parte das culturas juvenis, não só nos tempos de outrora, mas também nos jovens contemporâneos que encontro em minhas salas de aula. O fato é que muitas vezes, ao recebermos esses alunos, não há uma base conceitual clara e sólida, que já deveria ter sido trabalhada desde o ensino fundamental. Não quero aqui jogar a culpa para os 
professores dessa etapa formativa. O que se faz é a conclusão necessária de que, sem uma base clara para discussões em sala de aula, o professor pouco pode agir, devendo estar constantemente retomando os assuntos anteriores. Sobre essa temática da inconformidade com gerações anteriores ou com o momento atual estabelecido, outro autor muito conhecido e admirado nos estudos de culturas juvenis, Pais (2003, p.44), já nos aponta que "[...] as culturas juvenis definem-se por relativa oposição à cultura dominante das gerações mais velhas, como uma forma de 'resistência' à cultura da 'classe dominante', quando não mesmo a sua expressão linear".

Mas, como favorecer um ambiente adequado de aprendizagem a esse aluno para que possa discutir e formular ideias do que pensa de diferente em relação às gerações mais velhas? É possível, em sala de aula, estabelecer, com os alunos, padrões de como eram seus pais quando jovens e quais as relações sociais que os mesmos tinham. A resistência, aqui descrita, não somente se refere ao meio social, mas, também, na sala de aula. Quantas e quantas vezes nós, professores, e nossas propostas, são alvo de resistência dos alunos! O fato é que, em alguns casos, infelizmente, o aluno tem razão em não querer realizar determinadas tarefas ou propostas. Entretanto, em muitos outros casos - e acredito que em sua maioria - o aluno cria resistência ao trabalho proposto, mesmo sabendo que isso acarretará em seu crescimento caso o faça, porque não há empatia com o professor que o propõe.

Nesse sentido, comecei a perceber que, mais que simplesmente "dar aula", é necessário dialogar com o jovem, ouvi-lo, escutá-lo, estar atento ao que vem falando, como vem se portando e as suas preocupações. Há os que dirão que é tarefa árdua, trabalhosa e impossível. De fato, não há como conhecer particularmente cada aluno, com seus problemas e inquietações! Mas, "[...] compreender o que é ser jovem exige escuta, pois a realidade poderá ser diferente e, para se chegar a ela, torna-se necessário penetrar nos meandros do quotidiano dos jovens" (STECANELA, (2010, p.55) Já nos afirma Pais (2003, p.70): "Percebo também, que para 'penetrar nos meandros dos jovens', não basta apenas estar em seu meio, ingressar na sala de aula e dar aula". Há que ter escuta qualificada e disponível às suas ansiedades. Quando circulo no meio da sala de aula e converso com os alunos, percebo, efetivamente, quem eles são: pessoas jovens com muitas dúvidas, muitas incertezas, algumas verdades de mundo e muitos outros atributos morais, sociais, intelectuais e sentimentais. E são nesses meandros das culturas juvenis que percebo o quão rica é a realidade vivida e sonhada pelos jovens. O mundo da diversidade encontrado em uma escola é tão grande que dar conta de toda esta discussão em uma pesquisa apenas seria ilusão, porém, não podemos, de outro lado, dar às costas para tamanha riqueza teórica e conceitual, mas, acima de tudo, prática. Pais (2003, p. 98) continua e defende “[...] que a juventude deva ser olhada "não apenas na sua aparente unidade, mas também na sua diversidade", pois não há um único conceito de juventude, que possa envolver todos os campos semânticos que a ela estão associados".

Nem em termos conceituais nem na gama incontável de diversidade humana conseguiríamos discutir e formular um padrão único para as juventudes contemporâneas. Contudo, há que delimitarmos, para fins óbvios da pesquisa, alguns aspectos importantes e relevantes para serem questionados, referentes aos jovens que encontro diariamente em meus espaços de trabalho. Esses dados foram selecionados para a pesquisa pela evidência que tomaram em meu cotidiano docente. Acredito que qualquer docente também os tenha percebido, porém, me atrevo a questionar os jovens sobre: suas residências, suas idades, suas cores de pele, sua sexualidade, seus gostos musicais e literários, seus hábitos coletivos e particulares, entre outros, que serão explicitados no questionário da metodologia de pesquisa. Nessas informações encontramos relações diretas com a Geografia, pois não somente os comportamentos dos jovens, como também eles mesmos, são Geografia!

Ao questionar o sujeito jovem sobre seus espaços, dentro e fora da escola, há que nos remetermos às relações de poder, claras e automaticamente efetuadas nesses espaços. Falamos, então, das relações territoriais dos sujeitos jovens. Feixa $(1998$, p.87) já nos aponta que "[...] a relação dos jovens com o território é das mais significativas perspectivas de análise das culturas juvenis, considerando que historicamente, se constituíram com fenômeno essencialmente urbano". As culturas juvenis que despontam como um fenômeno urbano podem amplamente serem trazidas para as aulas de Geografia. Eu, particularmente, em minhas aulas, estou dispensando tempo em discutir com maior profundidade os fenômenos e processos urbanos, dado que nossa constituição, nas escolas que trabalho em Porto Alegre, é majoritariamente urbana. Nossos alunos transitam pela cidade, muitas vezes sem notar as marcas do espaço e como nós mesmos grafamos a cidade com nosso vai-e-vem cotidiano. Alertar o jovem contemporâneo para isso também é parte da aula de Geografia. Não quero aqui encher mais do que já está cheia a grade de conteúdos e programas curriculares a serem cumpridos. Minha intenção, verdadeiramente, é aportar minhas 
percepções de sala de aula, juntamente com minhas leituras, de como trazer à realidade as vivências dos alunos-jovens contemporâneos, e problematizar, discutir e comparar estas evidências nas aulas de Geografia. Ao questionar meus alunos sobre os espaços que mais gostam de frequentar, sejam eles na escola ou na cidade, refiro-me ao conceito de "espaço social praticado", já alertado por Stecanela (2010, p.65) quando afirma que

[...] os "espaços sociais praticados", especialmente no tempo livre dos jovens, contribuem para a constituição de redes de sociabilidade que, por sua vez, ajudam na construção das múltiplas identidades juvenis, a partir da relação consigo, com o outro, com o grupo e com a cidade.

Em Porto Alegre, por exemplo, um espaço de encontro semanal das diferentes tribos de jovens é o Parque Farroupilha, mais conhecido como Parque da Redenção, localizado próximo ao centro de cidade e também muito próximo ao Colégio Estadual Júlio de Castilhos. Aos sábados e domingos pela tarde ocorrem verdadeiras manchas no espaço, se analisamos por imagens aéreas. Os diferentes grupos se reúnem, e, quando não há invasão territorial de um elemento de um grupo em outro território que não o seu, o convívio ocorre tranquilamente. Um exemplo são os grupos de "Cosplay" (Costume Play - representação de personagem a caráter), os quais são grupos de atividades lúdicas praticadas em sua maioria por jovens, que consiste em se disfarçar ou se paramentar de algum personagem real ou fictício de algum anime (desenho animado japonês), mangá (quadrinhos japoneses), revista em quadrinhos ou similar.

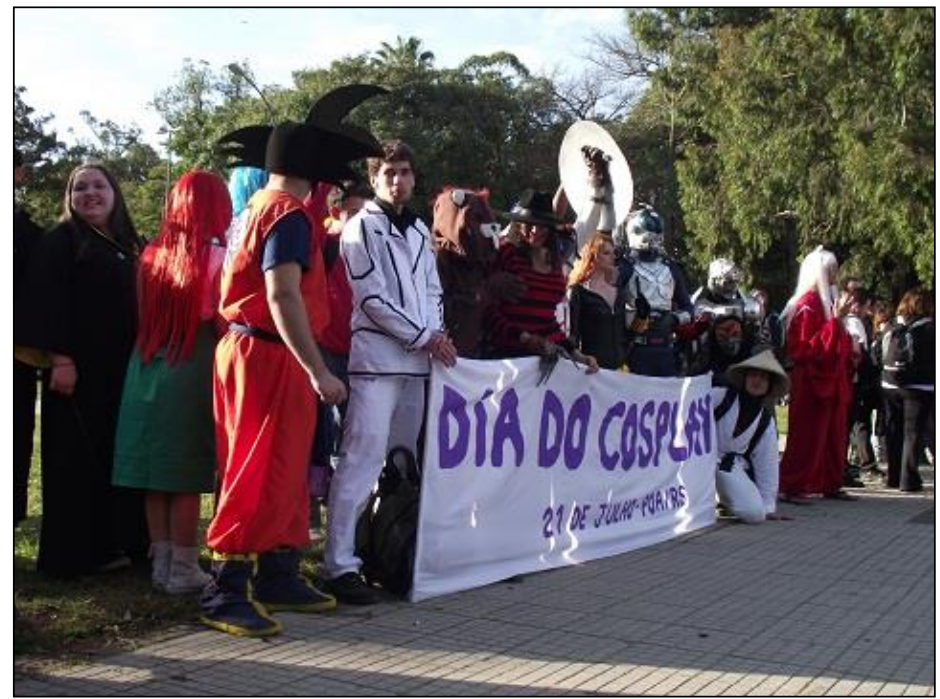

Figura 1: "Exemplo de uma das tribos encontradas no Parque da Redenção em Porto Alegre"

Fonte: Acervo do autor (2015).

Ressaltamos que essa mesma juventude encontrada na foto é a recebida nos bancos escolares. Como lidar com essas diferentes maneiras de ver o mundo? $\mathrm{O}$ que, de fato, têm a ver essas fantasias e vestimentas com o que tratamos em sala de aula? Esses são exemplos de questionamentos que venho me fazendo, ao encontrar na sala de aula, por exemplo, algumas vezes, alunos fantasiados com roupas de "anime", festivais de desenhos relacionados à cultura japonesa. Ir além do óbvio, nesse caso, que seria aproveitar o ensejo e falar sobre a "Geografia do Japão". É falar também de como a indústria cultural vem modificando nosso cotidiano e nos inserindo, cada vez mais, no mundo globalizado no qual vivemos. Não se pode falar das relações dos jovens com o mundo globalizado sem falar e questioná-los sobre a forma com a qual a internet está bricolada em sua rotina e suas vivências. Sobre isso, encontramos apoio nos estudos de Garbin (2009, p.18), quando versa sobre as culturas juvenis contemporâneas e as diferentes facetas destas culturas, que encontram na internet a sociabilização, como novas formas de se relacionarem: “[...] para os jovens do século XXI, dada a centralidade das tecnologias digitais nas quais foram nascidos e criados conectados à Rede, a comunicação com os outros passa a ser base de quase todas as suas relações" .

Posso afirmar que não há uma aula na qual não perceba ao menos um aluno mexendo, nem que apenas uma vez, em seu aparelho de smartphone, atualizando ou verificando seu status no Facebook, WhatsApp, 
Twitter, Instagran ou outra rede social. Há que ceder às pressões da tecnologia? Há que aboli-las, abruptamente, de nossa sala de aula? Nem tão ao céu, nem tão ao inferno. O bom senso, nessas horas, ajuda. Confesso que permito o uso do telefone celular, para fins de pesquisa em sala de aula, quando autorizado por mim. Na era da informação há que saber ensinar ao aluno a filtrar o que vê na internet e transformar esta informação em conhecimento, e posteriormente, em sabedoria para sua vida.

Outro processo que percebo claramente, principalmente com alunos dos turnos da tarde e noite no Colégio Estadual Júlio de Castilhos, trata-se da "dilatação da juventude", onde um grupo considerável de alunos permanece na escola - muitas vezes forçando sua reprovação - com o intuito de manter seus contratos com estágios e/ou bolsas de emprego. Daí a intenção de questionar a relação série/idade do aluno, verificando este ponto, bem como, posteriormente, a análise dos índices de reprovação. Sobre a dilatação da juventude, Canevacci (2005, p.102), nos aponta que "[...] é possível 'dilatar' a permanência na categoria jovem, se o sujeito continuar estudando, ou passar para a vida adulta entrando logo no mercado de trabalho". Esta é a realidade que vejo muitas vezes: sujeitos jovens, mas com responsabilidades de adultos, já mantendo uma vida financeira ativa e colaborando de maneira significativa na economia de suas casas.

Quem são os jovens contemporâneos? Como tratar as culturas juvenis em sala de aula hoje? Serrano (1998, p.118) já nos intui a pensar no sentido de que

[...] talvez las culturas juveniles hoy más que ser una contracultura se pesentan como la expresión evidente de lo que son las tendencias del momento actual, de las cuales ellos son unos de los interpretes de una partitura que tocamos todos, de una gran representación en la que somos actores y espectadores.

Serrano (1998) incita o debate das culturas juvenis como a expressão das tendências do momento atual. $\mathrm{E}$, de fato, os jovens apresentam o estereótipo de imortalidade, força, ultrapassagem de barreiras. Certamente também todos nós estamos envolvidos nessa "grande representação" apontada pelo autor, muitas vezes observando e seguindo regras sociais impostas pelas mídias e outras vezes ditando estas regras para nossos alunos. Ser jovem é eterno e não passageiro, o espírito da juventude pode fazer parte da vida de uma senhora de muitos anos de vida. Ser jovem é ver o mundo com o olhar do novo e estar aberto às mudanças dos novos tempos.

Nesse emaranhado de redes e conceitos para melhor entender os processos que perpassam as múltiplas identidades dos jovens, surge a identidade de aluno - importante para a presente pesquisa - já que é o elo entre as identidades já anunciadas e o ensino de Geografia. Neste sentido, Xavier (2014, p.101) nos alerta que o processo de construção social da categoria "aluno" não se dá naturalmente na relação de sala de aula, na medida em que "[...] a incorporação [das crianças] a uma instituição do Estado como é a escola, regida por um conjunto de convenções novas e [...] em grande parte desconhecidas, supõe a internalização dessas convenções para sua transformação [na] categoria social [...] de alunos" .

Sob essa ótica fica claro que, para que a criação da identidade do aluno se efetive, não basta apenas criarmos e colocarmos em prática as normas e o regramento tão costumeiros em nossas escolas. Há que perpassarmos por uma questão histórica de culturas escolares, muitas vezes passadas de pais para filhos, com as quais não nos deparamos, atualmente, em nossas salas de aula. $\mathrm{O}$ aluno não chega pronto à escola. $\mathrm{O}$ professor também não. Trata-se de processos que ocorrem a cada geração, os quais estão plenamente imbuídos de convenções atitudinais, morais, éticas e culturais. É nossa intenção aprofundar este tema durante os desdobramentos dos achados da pesquisa, uma vez que trabalharemos com muitos dados encontrados e poderemos correlacioná-los com os conceitos já apresentados aqui. Vejamos as relações entre os jovens contemporâneos e o ensino de Geografia.

\section{DE JOVENS E DO ENSINO DE GEOGRAFIA}

Como pensar uma Geografia para os jovens? Quais aportes teóricos e metodológicos devem portar o professor de Geografia, em relação ao conhecimento dos/nos sujeitos-jovens-alunos? Há que se elucidar o leitor que, após densa pesquisa bibliográfica, pouquíssimos materiais trabalham diretamente com a relação do ensino de Geografia e os Jovens Contemporâneos/Culturas Juvenis. O que encontrei aqui foram materiais que ou tangenciam a temática e podem me ajudar na discussão proposta, ou que falam diretamente sobre o ensino de Geografia, e coloco, neste momento, para a discussão e elaboração das redes de conceitos necessárias à pesquisa. Ao ingressarmos no tocante ao ensino de Geografia, há que ressaltarmos o que é a Geografia Escolar! Como já 
nos alerta Cavalcanti (2008, p.23), trata-se da ciência que possui uma especificidade “[...] que advém em parte dos conhecimentos acadêmicos, em parte do movimento autônomo dos processos e práticas escolares e em parte das indicações formuladas em outras instâncias, como as diretrizes curriculares e os livros didáticos" .

Ou seja, não estamos tratando aqui das temáticas puras e aplicadas da Geografia, como: Geografia Urbana, Climatologia, Geografia dos Conflitos Mundiais, ou outra subdivisão qualquer. Em Geografia Escolar, entendemos este tríplice movimento: a) conhecimentos acadêmicos; b) práticas escolares; e c) diretrizes curriculares e livros didáticos. Logo, é errônea a concepção de que a Geografia ensinada na escola seria uma cópia do que a academia pura e simplesmente está produzindo. A Geografia Escolar tem vida própria, e vai se estabelecendo como tal, cada vez mais aumentando sua pesquisa e debate. Penso que a maior discussão na atualidade é a função da Geografia e de seu professor.

Vivemos na sociedade da rapidez e da informação, isto é inegável. Em tempos onde as informações percorrem o mundo em velocidades incríveis e os jovens acompanham com muita facilidade estas transformações e esta velocidade, o professor de Geografia deve saber como reinventar sua prática pedagógica, uma vez que já nos alertava Lacoste (1988, p.96) que, "no caso da geografia, a relação pedagógica veio a ser transtornada, pois o mestre não tem mais como outrora e como ainda acontece em outras disciplinas, o monopólio da informação". O que fica muito claro para mim é o seguinte: em se tratando de jovens alunos contemporâneos, a aula, quando é depósito de informações, pouco tem valor. O que chama atenção dos jovens, e principalmente na aula de Geografia, é quando a informação passa a ter sentido e se transforma em conhecimento, mais ainda se o conhecimento se aplica a situações cotidianas e se transforma em sabedoria. E este processo não compreendemos como tarefa de fácil resolução. Há que efetuar o planejamento de aulas com muita atenção, para que o que for trabalhado possa de fato corroborar na construção do conhecimento e sua consequente aplicação em situações reais. Conforme Castrogiovanni (2011, p.79) há que estar atento ao fato de que "[...] o conhecimento é a representação da realidade através das formas de linguagem. Portanto, por sermos inteligentes, o conhecimento transforma-se através do tempo, assumindo verdades provisórias no presente".

Logo, o que é verdade hoje, amanhã pode não ser. O fato é que está sendo apresentada como verdade hoje, agora. Entender melhor quem é meu aluno é, portanto, uma maneira de saber como trabalhar estas informações com eles e, desta forma, a partir da condução dos conhecimentos geográficos de seu cotidiano, fazendo com que os mesmos tenham sentido e tornem-se, de fato, conhecimento.

Nesse sentido, voltamos à discussão curricular. Grenn e Bigun (1995, p.66), nos questionam: "Têm as escolas e as autoridades educacionais desenvolvido currículos baseados em pressupostos essencialmente inadequados e mesmo obsoletos sobre a natureza dos/as estudantes?"

Que currículo, para quais alunos? Procuro, em minha prática docente, instigar o aluno para que perceba, como já dito, que a realidade que o circunda também é Geografia. Esta pesquisa propõe-se a verificar, nesse sentido, qual o papel do ensino de Geografia para os jovens contemporâneos e, desta forma, também contribuir humildemente na discussão curricular da disciplina. Cavalcanti $(2011$, p.55) complementa a discussão curricular e adiciona a questão das pesquisas em ensino de Geografia, as quais são realizadas na contemporaneidade, ao acenar que

[...] a reflexão sobre o que ensinar em Geografia, tendo em vista a sociedade contemporânea e suas demandas, tem sido uma preocupação de muitos investigadores de ensino e de muitos professores, no Brasil e em outros lugares do mundo, devido ao interesse que se tem em aproximar o ensino dessa matéria às demandas formativas da sociedade, em permanente e acelerada transformação. [grifo nosso].

Não basta apenas ficarmos no âmbito das pesquisas ou da preocupação. Acredito que é necessário, também, partir para a ação. Como, de fato e efetivamente, o professor de Geografia pode aproximar suas aulas à realidade circundante? Defendo a tese de que conhecer melhor seu aluno, e, a partir disto, pensar em suas aulas, aproximando-as da realidade do mesmo, é a melhor forma de conquistá-lo em termos afetivos e cognitivos. Ou seja, quando o aluno percebe que o professor está interessado nele, e não apenas em encaminhar uma lista de conteúdos, torna-se aberto ao que se propõe e, ao mesmo tempo, as chances reais de o aprendizado acontecer são enormemente maiores.

Falar sobre Geografia escolar é também pensar no professor de Geografia. Kimura (2010, p.77) afirma-nos que, "[...] diante da dificuldade de uma leitura do mundo, o trabalho do professor de Geografia torna-se muito mais complexo". E quão complexo é o trabalho do professor de Geografia na atualidade, com

ParaOnde!?, Porto Alegre, v.10, n.2, p.125-134, 2018. Edição Especial com artigos publicados originalmente na XII ENANPEGE http://seer.ufrgs.br/paraonde 
a carga imensa de informações que são despejadas diariamente sobre nossos alunos-jovens, e sobre cada um de nós. $\mathrm{O}$ trabalho em sala de aula, que deve ir além da mera, pura e simples informação, passa a se tornar complexo no sentido de que cabe também ao professor a seleção daquilo que colocará em prática/discussão de tudo o que vem acontecendo na realidade. A mesma autora segue na discussão da relação do professor de Geografia com seu aluno, a qual, muitas vezes, torna-se complicada e complexa, dadas as relações de empatias ou não formadas entre alunos e professor. Sabemos que nem todos os professores são do agrado de todas as turmas, e isto é absolutamente normal, dado que entramos na seara das relações interpessoais. Kimura (2010, p.45) nos alerta para que a Geografia seja um ponto de ligação entre alunos e professores, na medida em que o professor se utiliza da mediação dos conhecimentos para aproximar-se de seus alunos (jovens):

O professor pode encontrar na relação dialógica com o aluno um caminho que ofereça pistas com possíveis esclarecimentos sobre as razões de os alunos fazerem uma determinada representação do mundo pouco usual para a Geografia. Este é um bom modelo de partida para o aluno ir incorporando e acrescentando novas apreensões sobre a realidade, tendo na mediação do professor de Geografia, as possibilidades de construir novas referências.

E essa relação dialógica, em alguns casos, pode encontrar conflitos, na sala de aula, na escola e em outros espaços. Castellar (2011, p.145) aponta para a necessidade de compreensão da realidade do aluno, para que os conflitos que porventura possam surgir sejam motivos para a compressão de uma realidade toda mais complexa do que apenas o mundo escolar:

[...] ao entender esses conflitos existentes na escola que a aula pode fazer diferença, conforme o aluno, ao ser colocado em situação de desafios, é estimulado a estabelecer nexos entre o que aprende e a realidade, o que pode lhe dar instrumentos para romper com as desigualdades.

Com essa fala quero lembrar a importância dos conflitos presentes na escola e de como as aulas de Geografia podem romper e acrescentar novos conhecimentos aos alunos, já que estes podem - e deveriam ser constantemente estimulados.

Fazer da aula de Geografia um espaço para pensar nossa constituição como sujeitos é colocar a realidade a nossa frente e, a partir dela, pensar sobre o mundo e como nós o interpretamos. Já afirma Kaercher (2011, p.206), que "[...] a aula de Geografia pode contribuir para fazer as pessoas pensarem suas imagens de mundo, o modo como foram construídas, as razões pelas quais se mantém e as maneiras outras de imaginar esse mesmo mundo".

Nesse sentido, percebemos a importância da aula de Geografia e a sua real contribuição. O sujeitojovem-aluno, com seus anseios e inquietações, também possui imagens de mundo e é dever do professor de Geografia ajudá-lo a interpretar estas imagens, bem como as maneiras de imaginar o mundo. Um exemplo para estimular isso seria através das ferramentas da "perguntação", já apontadas por Kaercher (2011). Perguntar sobre as visões de mundo dos alunos e suas representações, bem como sobre as mais variadas formas de percepção do espaço forma parte de estratégias conceituais fundamentais para a construção das relações espaciais dos jovens.

Em suma, "[...] a Geografia escolar não se ensina. Ela se constrói, ela se realiza". (CAVALCANTI, 2008, p.45). A Geografia escolar se realiza em nosso cotidiano docente, quando estamos trabalhando não apenas os conceitos que nos cabem, mas a diversidade que encontramos em sala de aula e como esta diversidade pode nos ajudar a melhor docenciar, a sermos melhores professores. Para trabalharmos com estes sujeitos-jovens, é preciso conhecê-los melhor: e é a isto que este trabalho se dedica!

\section{4. À GUISA dA CONCLUSÃo: PARA NOVAS LEITURAS DE JOVENS E DE GEOGRAFIA ESCOLAR...}

Pareceu-nos muito claro que as relações efetuadas entre esse jovem contemporâneo e o ensino de Geografia estão ligadas aos temas físicos da ciência. Quando questionamos os mesmos sobre a "serventia da Geografia", nos são oferecidas como respostas as temáticas físicas (duras) da ciência geográfica, como localizar países ou saber fusos horários, por exemplo. Se perguntarmos ainda quais são as palavras que mais lembram a Geografia, os mesmos inferem, em sua maioria, em palavras da ordem da Geografia física.

Essa constatação nos faz refletir sobre como vem sendo dada a condução de nossas aulas e sobre como

\footnotetext{
Para0nde!?, Porto Alegre, v.10, n.2, p.125-134, 2018. Edição Especial com artigos publicados originalmente na XII ENANPEGE
} http://seer.ufrgs.br/paraonde 
vem sendo pensados os currículos escolares e os programas de ensino. Vejamos alguns questionamentos importantes:

a) sobre nossas aulas:

- Estamos dando a verdadeira importância ao conceito de Espaço Geográfico e suas relações entre os temas sociais e naturais?

- Estamos contextualizando as realidades locais dos alunos, de maneira a termos uma abordagem das diferentes escalas geográficas, partindo do local e chegando ao global (e vice-versa)?

- Estamos tendo espaço para discutir com os alunos as temáticas dos movimentos sociais, das cidades, das populações, de maneira com que eles se sintam participantes destas questões?

- Não estaríamos frisando em demasia o tema físico da Geografia, uma vez que, no imaginário popular, o mesmo dá mais "validade" à ciência geográfica?

b) Sobre os currículos escolares e os programas de ensino:

- Estamos balanceando as temáticas físicas com as temáticas humanas da Geografia, ao planejarmos nossos planos de ensino?

- Estamos conseguindo efetuar a devida defesa da permanência da Geografia nas grades de currículos, quando sabemos que em muitas escolas não há mais Geografia nos três anos do ensino médio?

- Estamos cientes das propostas dos órgãos competentes (Ministério e Secretarias de Educação) no que diz respeito ao ensino de Geografia?

Caro leitor, são muitas as perguntas! Encontramos respostas para elas? Nesse sentido é que nos referimos ao afirmar que a busca por responder uma pergunta nos abre espaço para outras tão urgentes quanto a primeira.

Acredito ser importante lembrar, neste espaço, Meirieu (2006, p.25), em sua "Carta a um Jovem Professor", sobre uma visão importante do professor: "Não há nada de extraordinário, então, em considerarmos nosso ofício como um meio de possibilitar a outros que vivam a alegria das descobertas que nós próprios vivemos".

E, ainda, uma visão importante sobre o conhecimento, ainda conforme as palavras do autor (2006, p.19): "O professor deve possibilitar a cada aluno confrontar-se com um saber que o ultrapassa e, ao mesmo tempo, fornecer-lhe a ajuda necessária para se aproximar deste saber".

Avante, companheiros! Há muito trabalho a ser feito! Mais pesquisas, mais aulas, mais jovens e mais reflexões virão!

\section{REFERÊNCIAS}

CACCIA-BAVA, Augusto; COSTA, Dora Isabel Paiva da. O lugar dos jovens na história brasileira. In: ; FEIXA PAMPOLS, Carles; CANGAS, Yanko. (Orgs). Jovens na América Latina. São Paulo: Escrituras Editora, 2004.

CANEVACCI, Massimo. Culturas eXtremas: mutações juvenis nos corpos das metrópoles. Rio de Janeiro: DP\&A, 2005.

CASTELLAR, Sonia Maria Vanzella. Mudanças na prática docente: a aprendizagem em espaços não formais. In: REGO, Nelson et al. Geografia: práticas pedagógicas para o ensino médio. Porto Alegre: Penso, 2011.

CASTROGIOVANNI, Antônio Carlos. Diferentes conceitos nas complexas práticas de Ensino em Geografia. In: TONINI, Ivaine Maria et. al. (Orgs). O ensino da geografia e suas composições curriculares. Porto Alegre: Editora da UFRGS, 2011.

CAVALCANTI, Lana de Souza. A geografia escolar e a cidade: ensaios sobre o ensino de geografia para a vida urbana cotidiana. Campinas: Papirus, 2008.

. A Geografia Escolar e a Sociedade Brasileira Contemporânea. In: TONINI, Ivaine Maria et. al. (Orgs). O ensino da geografia e suas composições curriculares. Porto Alegre: Editora da UFRGS, 2011.

ParaOnde!?, Porto Alegre, v.10, n.2, p.125-134, 2018. Edição Especial com artigos publicados originalmente na XII ENANPEGE http://seer.ufrgs.br/paraonde 
. Aprender sobre a cidade: a geografia urbana brasileira e a formação de jovens escolares. Revista Geográfica de América Central Número Especial EGAL, Costa Rica II Semestre 2011.

FERREIRA, Débora Schardosin. Canoas como lugar: o mundo dos jovens contemporâneos a partir de suas representações sociais. (Dissertação de Mestrado), Pós-Graduação em Geografia. Instituto de Geociências. Universidade Federal do Rio Grande do Sul. Porto Alegre, 2014.

FEIXA PAMPOLS, Carles. A construção histórica da juventude. In: CANGAS, Yanko. (Orgs). Jovens na América Latina. São Paulo: Escrituras, 2004.

CACCIA-BAVA, Augusto;

La ciudad invisible: territórios de las culturas juveniles. In: MARGULIS, Mario; CUBIDES, Humberto; VALDERRAMA, Carlos. Viviendo a toda: jóvenes, territórios culturales y nuevas sensibilidades. Santa Fé de Bogotá: Universidad Central; Siglo Del Hombre, 1998.

GARBIN, Elisabete Maria. Conectados por um fio: alguns apontamentos sobre internet, culturas juvenis contemporâneas e a escola. In: Juventude e escolarização: os sentidos do Ensino Médio. Programa Salto para o Futuro - TVE/Escola/Brasil. São Paulo, ano XIX, Boletim 18, nov./2009.

GARBIN, Elisabete Maria; TONINI, Ivaine Maria. "Geografando" práticas juvenis que (de)marcam a metrópole: uma questão de currículo escolar? Revista Geograficidade, Rio de Janeiro, v.2. Número Especial, Primavera, 2012.

GREEN, Bill \& BIGUN, Chris. Alienígenas na sala de aula. In: SILVA, Tomaz Tadeu. (Org). Alienígenas na sala de aula - uma introdução aos estudos culturais em educação. Petrópolis: Vozes, 1995.

KAERCHER, Nestor André. Das coisas sem Rosa uma delas é o Pessoa: as Geografias do Manoel e do Nestor na busca do bom professor. In: TONINI, Ivaine Maria et. al. (Orgs). O ensino da geografia e suas composições curriculares. Porto Alegre: Editora da UFRGS,

2011.

KIMURA, Shoko. Geografia no ensino básico. São Paulo: Contexto, 2010.

LACOSTE, Yves. A Geografia - isso serve, em primeiro lugar, para fazer a guerra. Campinas: Papirus, 1988.

PAIS, José Machado. Culturas Juvenis. Lisboa: Imprensa Nacional-Casa da Moeda, 2003.

PIRES, Cláudia Luiza Zeferino; SIMÃO, Ana Regina Falkembach; POZZER, Kátia Maria Paim. Representações Espaciais, Juventude e Periferia: Guajuvira/Canoas/RS e seus desafios urbanos. Revista FSA, Teresina, v.10, n.1, art.7, p. 118-38, jan./mar. 2013.

SERRANO, José Fernando. 'Somos el extremo de las coisas': o pistas para comprender culturas juveniles hoy. In: CUBIDES, Humberto J., TOSCANO, María Cristina Laverde,

VALDERRAMA, Carlos Eduardo H. "Viviendo a toda" - Jóvenes, territorios culturales y nuevas sensibilidades. Série Encuentros, Fundación Universidad Central, Santafé de Bogotá: Paidós, 1998.

STECANELA, Nilda. Jovens e Cotidiano: trânsitos pelas culturas juvenis e pela escola da vida. Caxias do Sul: Ediucs, 2010.

XAVIER, Maria Luísa Merino de Freitas. A construção da categoria social aluno: aprendizagens, socialização e disciplinamento em questão. Currículo sem Fronteiras, Porto Alegre, v.14, n.2, p. 97-108, maio/ago. 2014.

Para0nde!?, Porto Alegre, v.10, n.2, p.125-134, 2018. Edição Especial com artigos publicados originalmente na XII ENANPEGE http://seer.ufrgs.br/paraonde 